\title{
La ola de calor de octubre de 1995 en Navarra
}

\author{
Javier María Pejenaute Goñ *
}

\section{RESUMEN}

El mes de octubre de 1995 entra de lleno dentro de los períodos excepcionales que se vienen sucediendo en los últimos años en nuestra Comunidad. Las temperaturas tan altas, más bien propias del verano en un mes típicamente otoñal, hacen de este mes un período difícil de encontrar en las series históricas amplias que se poseen. El presente artículo tiene por objeto el estudio de este mes para conocer las causas y las repercusiones climáticas en las diferentes comarcas navarras. Para ello se han utilizado los datos proporcionados por más de ochenta observatorios de Navarra, bien repartidos por todo el territorio.

Palabras clave: Ola de calor, temperaturas elevadas, clima de Navarra, riesgos climáticos.

\section{SUMMARY}

The month of october 1995 fits wholy into the exceptional spells of weather that the Foral Community of Navarra has been having in the last few years. In fact, in the wide historical records kept, it is difficult to find an autumnal month with such high temperatures, characteristic of summer seasons. The article below has as its main aim to study this period and gey to know the causes and climatics effects on the different areas of Navarra. In order to do so, data from aver 80 observatories acattered all over Navarra have been used.

Key words: heat wave, high temperatures, the climate of Navarra, climatic risks.

* Profesor/Tutor del Centro Asociado de Navarra. 


\section{INTRODUCCIÓN}

El mes de octubre de 1995 ha sorprendido a los estudiosos de la climatología por la excepcionalidad de los resultados térmicos, superiores a los anotados hasta la actualidad en las series históricas más prolongadas que existen en Navarra. En efecto, la presencia de una circulación atmosférica sumamente original, más propia de la época estival que del otoño, dio lugar a unas temperaturas excesivamente elevadas, desconocidas en la mayor parte de observatorios, y la sucesión de días muy secos, que agudizaron el problema derivado de la prolongada sequía que tenemos.

En los últimos años se está observando en Navarra, cada vez con mayor asiduidad, tipos de tiempo que se salen de lo normal y que originan valores extremos bien percibidos por los ciudadanos. Un ejemplo de ello es la pertinaz sequia de 1995 que se viene padeciendo desde enero, originada principalmente por la escasa presencia de las lluvias de primavera, las únicas seguras en Navarra en los últimos años. Pese a todo esto es muy difícil afirmar que estos cambios sean originados por la agresión que sufre la atmósfera por parte del hombre, pues se trata de episodios concretos y locales. Cuando ocurren estos sucesos climáticos extremos a los que últimamente estamos tan acostumbrados, la opinión pública echa la culpa al trinomio efecto invernadero-agujero de la capa de ozono-cambio climático al que acompaña comúnmente la desertización. Conviene recordar en este sentido que el cambio climático es una hipótesis de trabajo, muy discutida, que todavia presenta algunas evidencias y muchas incógnitas sin aclarar.

El clima de Navarra no es ajeno a comportamientos climáticos violentos en los últimos años. Esto hace que una vez estudiados los valores medios que configuran nuestro clima adquieran importancia los tiempos extremos frecuentes en los últimos años. Estos tiempos raros que sobrepasan los límites de lo habitual tienen lugar cada vez más con mayor frecuencia, por lo que están más a menudo en el punto de mira de los climatólogos.

El objetivo de esta publicación es el estudio del mes de octubre de 1995, que ha llamado nuestra atención por sus valores térmicos elevados poco frecuentes. Se pretende primeramente averiguar las causas que han originado un período tan peculiar; en segundo lugar se analizan las temperaturas registradas en las comarcas navarras; y finalmente se estudia la diferenciación comarcal existente entre los distintos sectores de Navarra, con respecto al grado de calor, en un mes otoñal muy caluroso.

Para su estudio se han utilizado las tarjetas mensuales de temperaturas y de precipitaciones correspondientes a siete observatorios básicos 
(cuadro $n^{0} 1$ ), representativos de todas las comarcas navarras, fiables y en su mayor parte con series de larga duración. Para el estudio comarcal, se han trabajado los datos de numerosos observatorios de apoyo con que cuenta la amplia red navarra y se han seleccionado los que figuran en los gráficos por comarcas climáticas: Navarra Húmeda; Navarra Pirenaica; las Cuencas Intermedias; Navarra Media; y la Ribera Navarra '. También se han estudiado Las series históricas térmicas de los observatorios navarros de Santesteban (Navarra Húmeda), Abaurrea Alta (Navarra Pirenaica), Pamplona-observatorio (las Cuencas), Carcastillo (Navarra Media y la Ribera) desde el año 1941 hasta el año 1995.

\section{CUADRO 1. RED DE OBSERVATORIOS PRINCIPALES UTILIZADOS}

\begin{tabular}{lccc}
\hline & & \multicolumn{2}{c}{ COORDENADAS } \\
\cline { 3 - 4 } OBSERVATORIOS & ALTITUD (M.) & LONGITUD & LATITUD \\
\hline Santesteban & 131 & $43^{\circ} 08^{\prime} \mathrm{N}$. & $2^{\circ} 02^{\prime} \mathrm{E}$. \\
Abaurrea Alta & 1047 & $42^{\circ} 54^{\prime} \mathrm{N}$. & $2^{\circ} 29^{\prime} \mathrm{E}$. \\
Alsasua & 520 & $42^{\circ} 54^{\prime} \mathrm{N}$. & $1^{\circ} 31^{\prime} \mathrm{E}$. \\
Pamplona-Obs. & 449 & $42^{\circ} 49^{\prime} \mathrm{N}$. & $2^{\circ} 03^{\prime} \mathrm{E}$. \\
Yesa & 489 & $42^{\circ} 37^{\prime} \mathrm{N}$. & $2^{\circ} 30^{\prime} \mathrm{E}$. \\
Carcastillo & 340 & $42^{\circ} 22^{\prime} \mathrm{N}$. & $2^{\circ} 13^{\prime} \mathrm{E}$. \\
Fitero & 421 & $42^{\circ} 03^{\prime} \mathrm{N}$. & $1^{\circ} 50^{\prime} \mathrm{E}$. \\
Buñuel & 243 & $41^{\circ} 59^{\prime} \mathrm{N}$. & $2^{\circ} 15^{\prime} \mathrm{E}$. \\
\hline
\end{tabular}

Asimismo se han clasificado diariamente las situaciones atmosféricas por medio de los Boletines Meteorológicos Diarios elaborados por el Instituto Nacional de Meteorología, correspondientes a octubre de 1995, en superficie y en las topografías de 500 y de 300 milibares. Se han comparado sus resultados con los obtenidos en nuestra tesis doctoral relativos al mes de octubre.

También se ha contado con los datos suministrados por varias estaciones meteorológicas automáticas de Navarra, que nos han proporcionado

\footnotetext{
1 Se ha contado con los datos de los siguientes observatorios facilitados por el Servicio de Estructuras Agrarias del Gobierno de Navarra: Artikutza, Goizueta, Leitza, Betelu, Lesaka, Bera, Sunbilla, Santesteban, Bertiz, Zugarramurdi, Arizkun, Lekaroz para Navarra Húmeda; Valcarlos, Roncesvalles, Eugi, Erro, Aribe, Abaurrea Alta, Belagua, Navascuès, Esparza de Salazar y Urzainqui para Navarra Pirenaica; Olagüe, Alsasua, Irurtzun, Pamplona, Noain, llundain, Goñi, Urbasa, Monreal, Artieda, Aóiz para las Cuencas; Galbarra, Alloz, Puente la Reina, Estella, Viana, Olóriz, Yesa, Cáseda y Leyre para Navarra Media; y Caparroso, Carcastillo-la Oliva, Cadreita, Monteagudo, Buñuel, Fitero, Lerin, Lodosa y Sartaguda para la Ribera.
} 
datos diarios hora a hora de temperaturas, radiación solar en decenas de kilojulios por metro cuadrado, horas de sol diarias, humedad relativa diaria y dirección y velocidad del viento. Datos que ayudan todavía más a detectar las causas que han originado este mes atípico ${ }^{2}$.

\section{La dinámica atmosférica}

Las situaciones atmostéricas sumamente originales que se sucedieron durante el mes de octubre de 1995 explican los resultados anormalmente altos en cuanto a las temperaturas. En efecto, después de un mes de septiembre más frío de lo normal, octubre tuvo un grado de calor excesivamente elevado, difícil de encontrar en las series históricas, incluso en el observatorio de Pamplona que aporta datos desde finales del siglo XIX, concretamente desde el año 1880.

Dos tipos de situaciones atmosféricas principales afectaron a Navarra a lo largo del mes. Primeramente las anticiclónicas que supusieron más de la cuarta parte de los días $(29,03 \%)$; éstas se caracterizaron por proporcionar jornadas muy cálidas, dado que en las capas altas de la troposfera estaban coronadas por crestas o dorsales tropicales, habituales en verano y en septiembre, pero poco frecuentes en esta época del año. Junto a ellas, fueron dominantes, las situaciones meridionales del sur y del sudoeste que afectaron a más de la tercera parte de los días $(35,5 \%)$. Unas y otras, que representan casi las dos terceras partes de los días $(64,5 \%)$, fueron las verdaderas artífices de los dias muy cálidos de nuestra Comunidad.

Las demás situaciones, con porcentajes más modestos, también contribuyeron al caldeamiento general y aumento del grado de calor. Las situaciones del oeste $(12,9 \%)$ trajeron masas de aire atlánticas muy suaves, todavía sin enfriar, y sin lluvias, por lo que el ambiente caluroso continuó, mientras estuvieron presentes. Las del este y sudeste $(9,7 \%)$ por su procedencia dieron lugar a altos registros térmicos. $Y$ para terminar los pantanos barométricos y bajas térmicas $(6,5 \%$ cada una de ellas), pese a ser situaciones propias del estío, también aparecieron e hicieron aumentar el calor reinante.

\footnotetext{
2 Tengo que agradecer a la sección de Meteorología del Servicio de Estructuras Agrarias del Gobierno de Navarra la facilitación atenta de los datos. También, agradecer a Mikel ILARREGI, Meteorólogo de Energía Hidroeléctrica de Navarra los datos aportados sobre las estaciones automáticas.
} 
Esta primera aproximación demuestra las condiciones propicias de la atmósfera para obtener resultados térmicos elevados. Conviene recordar que las situaciones que dan lugar a descensos térmicos y temperaturas frías, es decir, las de primer y cuarto cuadrante, y los embolsamientos fríos sobre nuestra vertical, estuvieron ausentes, por lo que no hubo posibilidad de descensos térmicos acusados a lo largo del mes. Por otra parte, la escasa presencia de lluvia no contribuyó a refrescar el ambiente.

Así pues, dinámica atmosférica que se sale de lo que es habitual en el mes de octubre y muestra un predominio de situaciones más propias de la estación estival que del otoño. La alternancia de días anticiclónicos, que dan lugar a veranillos suaves, con borrascas del frente polar que producen lluvias y descensos térmicos, frecuentes en otoño, estuvieron ausentes, y dieron lugar a un mes sumamente original en el que se pueden distinguir tres fases principales.

La primera fase que abarca desde los inicios hasta el día 13 se caracteriza por su marcado carácter anticiclónico. El mes comienza con una situación propia de verano, con un pantano barométrico en superficie en los dos primeros días y una dorsal tropical en altura. Con esta situación, la radiación solar se dispara (Gráfico $n^{\circ} 1$ ), y supera ampliamente las cotas normales (Aóiz $1514 \mathrm{dKJ} / \mathrm{M} 2$; Carcastillo 1727,7 dKJL/M2). Lo mismo sucede con las horas de sol, que son numerosas para el mes de octubre (Aóiz 8,3 horas de sol; Carcastillo 9,4 horas de sol). Con estos valores las temperaturas se elevan y alcanzan los treinta grados de máxima y los quince de mínima en varios observatorios de los Valles Cantábricos y de la Ribera, que son los focos de mayor calor en Navarra. Por lo tanto, temperaturas que recuerdan, más bien, a un día cualquiera de verano. El viento bochorno del sudeste hizo más agobiante la jornada.

La dinámica atmosférica experimenta cambios durante los días siguientes( días 3 a 5) motivados por la llegada de una vaguada que atraviesa nuestro territorio de oeste a este. Una borrasca situada al noroeste de Escocia se abre camino entre dos anticiclones, uno situado al oeste que es el de las Azores y otro en la parte oriental, próximo a Europa Central. Los frentes fríos asociados, al atravesar la Comunidad, dan lugar a las únicas precipitaciones importantes registradas en este mes. En los Valles Pirenaicos y en la Cuenca de Pamplona se producen tormentas debido a la presencia de aire frío en altura $\left(-16^{\circ}\right.$ en la topografía de 500 $\mathrm{mb}$.). Se trata de una situación atmosférica normal en otoño que auguraba el comienzo de un mes con circulación atmosférica normal.

Con esta situación la radiación solar disminuye y alcanza uno de los valores más bajos del mes (Aóiz 902 dKJ/M2; Carcastillo 1043 dKJ/M2); lo 
mismo sucede con las horas de sol (Gráficos $n^{\circ} 1$ y 2), que son escasas debido a la nubosidad (Aóiz 4,3 horas de sol y Carcastillo 4 horas de sol). $Y$ esto, sin duda, repercute en las temperaturas, cuyas máximas se sitúan por debajo de los veinte grados, salvo en algunos observatorios de Navarra Media y de la Ribera; las temperaturas mínimas descienden a cinco grados en muchos lugares de Navarra. Así pues, se trata de un corto paréntesis de valores térmicos moderados dentro de un mes extraordinariamente cálido.

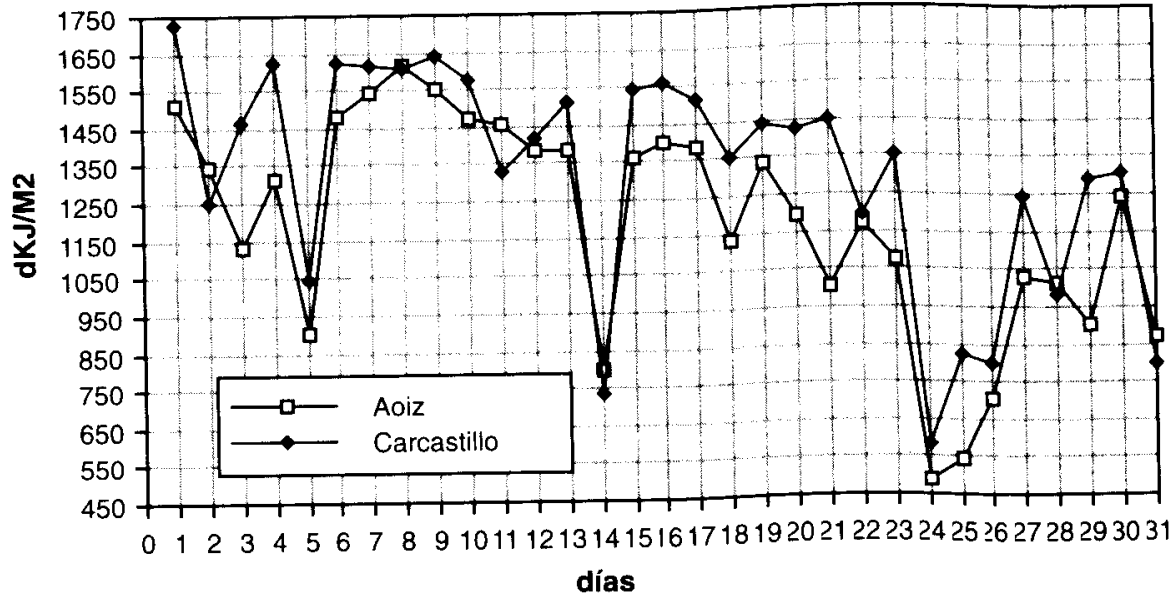

Gráfico 1. Aóiz y Carcastillo. Radiación solar en dKJ/M2

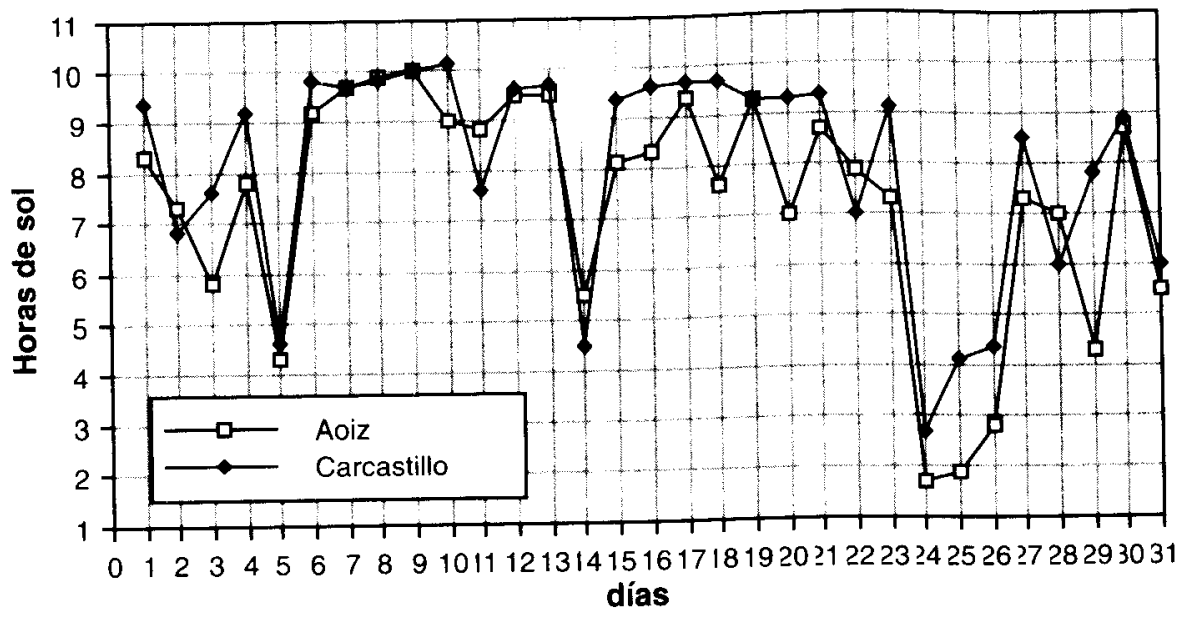

Gráfico 2. Aóiz y Carcastillo. Horas de sol. 
Tras el paso de esta fugaz borrasca se produce un aumento considerable del grado de calor que dura desde el día 6 al 13, originado por la entrada de un anticiclón cálido, que con orientación SO-NE., se extiende desde las Canarias hasta Escandinavia (Mapas 1 a, b, c y d). Se trata de una primera ola de calor. En superficie el anticiclón se centra en Europa Central y por su flanco oriental envía sobre nuestro territorio masas de aire de componente sur. En la topografía de 300 milibares la corriente en chorro es del sudoeste en el Atlántico Sur.

Este potente anticiclón ejerce una acción de bloqueo que tapona la entrada de la borrasca atlántica e impide la sucesión de los tiempos característicos de octubre, denominados veranillos al paso de las dorsales, y borrascas al paso de las vaguadas. En altura la corriente en chorro es ondulada y nuestro territorio se ubica dentro de la cresta anticiclónica, por lo que la presencia de lluvias y de un enfriamiento general es difícil.

Este tipo de situación atmosférica da lugar a días despejados caracterizados por una radiación solar alta, cuyo punto culminante es el día 8 con $1614 \mathrm{dKJ} / \mathrm{M} 2$ en Aóiz y el dia 9 en Carcastillo con $1638 \mathrm{dKJ} / \mathrm{M} 2$. En este mismo día se alcanzan las diez horas de sol en los citados observatorios (Gráficos 1 y 2).

Las temperaturas son elevadas durante este período comprendido entre los días seis y trece. El calor es mayor en los Valles Cantábricos, en donde las temperaturas máximas se sitúan todos los días, entre los veinticinco y los treinta grados, y las temperaturas mínimas entre los diez y trece grados. En la Cuenca de Pamplona, Navarra Media y la Ribera se alcanzan los veinticinco grados de máxima y los trece grados de mínima en varias jornadas. Finalmente en los Valles Pirenaicos, pese a su altitud, varios días registran temperaturas cercanas a veinte grados de máxima y diez de mínima. Valores térmicos muy altos para el mes que estamos, originados por la presencia de una dorsal tropical situada sobre nuestra vertical. Influidas por la misma, las masas de aire experimentan un calentamiento progresivo, estancadas en situación anticiclónica, con muchas horas de sol y alta radiación solar.

La segunda fase se extiende desde el día 14 al 23 y se caracteriza por la llegada de una nueva ola de calor, tras una pequeña interrupción. Los dias 14 y 15 supusieron un pequeño y corto descenso en las temperaturas originado por el paso de una vaguada que tímidamente afectó a Navarra, colándose por un ligero pasillo que se formó entre los dos centros de alta presión situados en las Azores y en el continente europeo. En la topografía de $500 \mathrm{mb}$. la temperatura es de $-16^{\circ}$ y en el mapa de $300 \mathrm{mb}$. se observa la llegada a nuestro territorio de dos ramales del oeste de la corriente en chorro. 


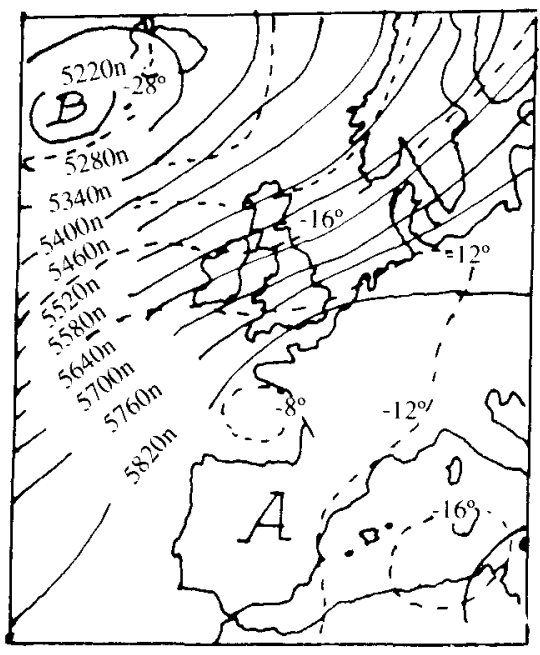

Mapa no 1.a - 500 mb. a 12 h. (TMG) Día 7-10-95

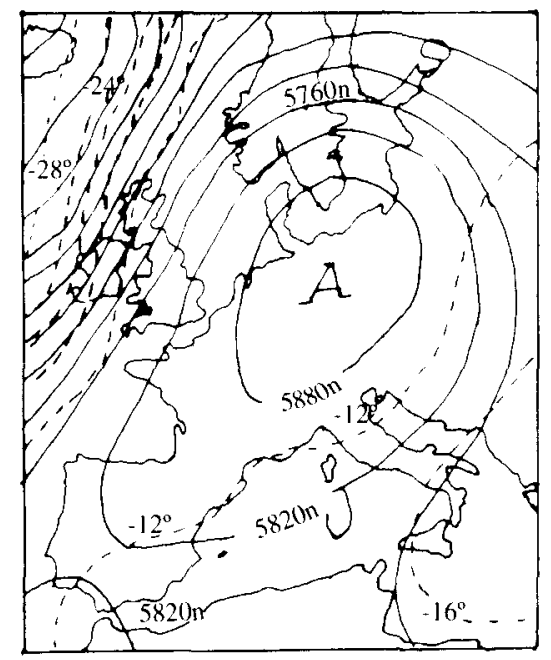

Mapa $\mathrm{n}^{\circ} 1 . \mathrm{c}-500 \mathrm{mb}$. a $12 \mathrm{~h}$. (TMG) Día 9-10-95

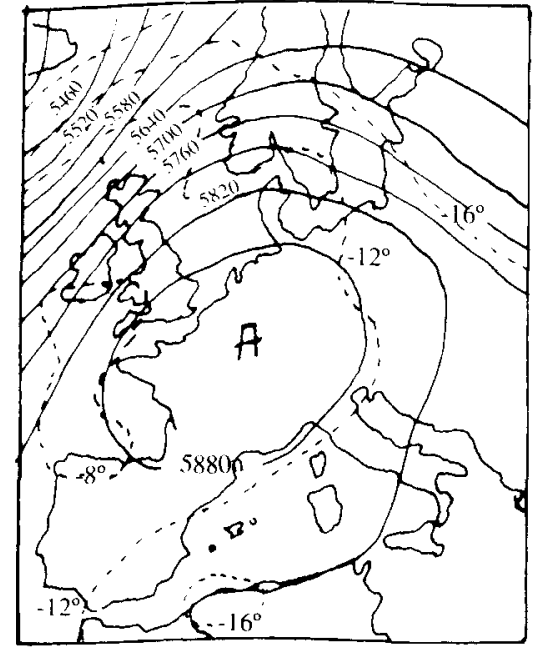

Mapa $n^{\circ} 1 . b-500 \mathrm{mb}$. a $12 \mathrm{~h}$. (TMG) Dia 8-10-95

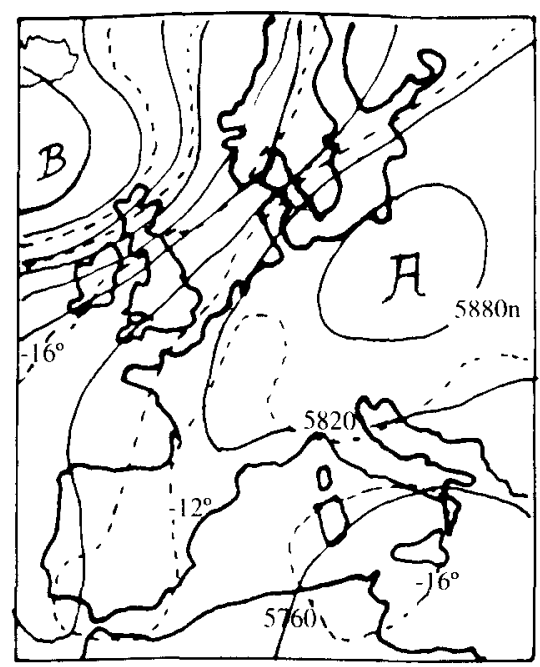

Mapa n $1 . d-500$ mb. a 12 h. (TMG) Dia 10-10-95

Mapa del tiempo 1

Con esta situación la radiación solar desciende debido al aumento de la nubosidad (día 14, Aóiz $796 \mathrm{dKJ} / \mathrm{M} 2$ y Carcastillo 737 dKJ/M2) y las horas de sol son inferiores (día 14, Aóiz 5,5 horas de sol y Carcastillo 4,5 horas de sol) (Gráficos 1 y 2). 
La llegada de la débil borrasca supone la aparición de escasas lluvias y un descenso de temperaturas, que, sin embargo, no es acusado. Las temperaturas máximas se sitúan próximas a los veinte grados en la mayor parte de Navarra (Santesteban $21^{\circ}$, Pamplona $18,6^{\circ}$, Carcastillo $22^{\circ}$, Abaurrea Alta $15^{\circ}$ ) y las temperaturas mínimas descienden por debajo de los diez grados.

Desde el día 16 al 23, correspondientes a esta segunda fase, tiene lugar la formación de una nueva situación anticiclónica que va a suponer un progresivo aumento de las temperaturas. En efecto, se produce una nueva reactivación de la circulación ondulada de altura, formada por dos borrascas, situadas en el Atlántico sur y en en el norte de África y una dorsal que, con orientación SO-NE, se extiende desde las Islas Canarias hasta el centro de Europa. Se trata de un nuevo anticiclón de bloqueo que impide la llegada de las borrascas y con ellas de las temperaturas moderadas y del enfriamiento general.

Una vez más esta circulación ondulada de altura permanece fija, sin trasladarse de oeste a este como es habitual en los meses normales de las estaciones equinocciales, con lo que el ambiente anticiclónico seco y soleado está garantizado. La corriente en chorro rodea las dos borrascas y pasa bordeando la cresta que protege nuestro territorio. Se trata de una dorsal cálida que origina tiempos despejados. De este modo, las masas de aire cálidas estancadas en nuestro territorio, sometidas a fuerte radiación solar experimentan fuertes calentamientos.

Con estas condiciones anticiclónicas cálidas la radiación solar es abundante durante todas estas jornadas, llegando el día diecinueve a cifras elevadas que se pueden observar en el gráfico 1 y 2 (Aóiz 1334 dKJ/M2 y 9,3 horas de sol; Carcastillo $1439 \mathrm{dKJ} / \mathrm{m} 2$ y 9,5 horas de sol). Las temperaturas máximas se mantienen elevadas dentro de este ambiente anticiclónico de veranillo prolongado, alcanzándose cifras altas (Santesteban $28^{\circ}$, Pamplona $24^{\circ}$, Carcastillo $27,5^{\circ}$, Abaurrea Alta $22^{\circ}$ ). Las temperaturas mínimas también son elevadas (Santesteban $15,5^{\circ}$, Pamplona $13,6^{\circ}$, Carcastillo $13,5^{\circ}$ y Abaurrea Alta $11^{\circ}$ ). Por lo tanto, valores térmicos muy superiores a los normales, que pueden aparecer aisladamente en alguna jornada, pero que en esta ocasión son raros por la persistencia continuada de la alta termometría.

La tercera fase comprende desde el día 24 hasta el final y supone una nueva reactivación del ambiente cálido con la entrada de masas de aire de componente meridional que van a mantener el ambiente caluroso de todo el mes y los registros térmicos en valores muy altos para finales de octubre. Si el mes ha sido cálido, es normal que se produzca al final un descenso térmico acusado que significa la entrada del otoño. Pero esta vez no fue asi y el calor continuó hasta la finalización del mes. 


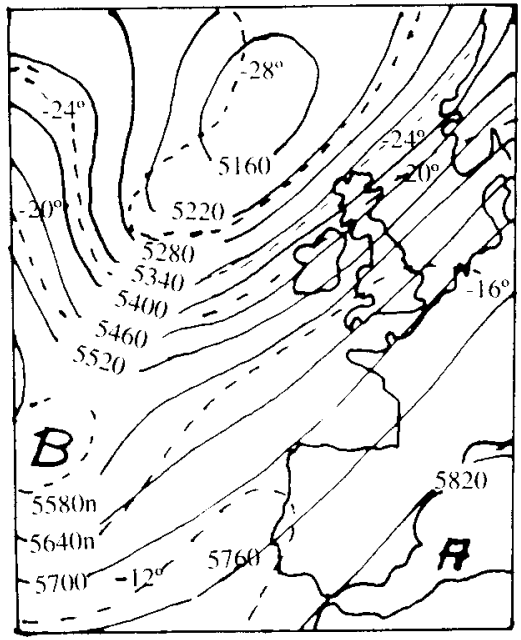

Mapa $\mathrm{n}^{\circ} 2 . \mathrm{a}-500 \mathrm{mb}$. a $12 \mathrm{~h}$. Día 26-10-95

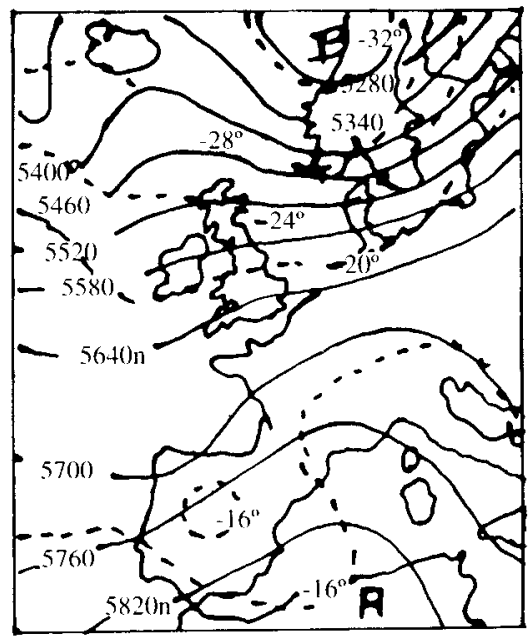

Mapa $n^{\circ} 2 . c-500 \mathrm{mb}$. a $12 \mathrm{~h}$. (TMG) Día 28-10-95

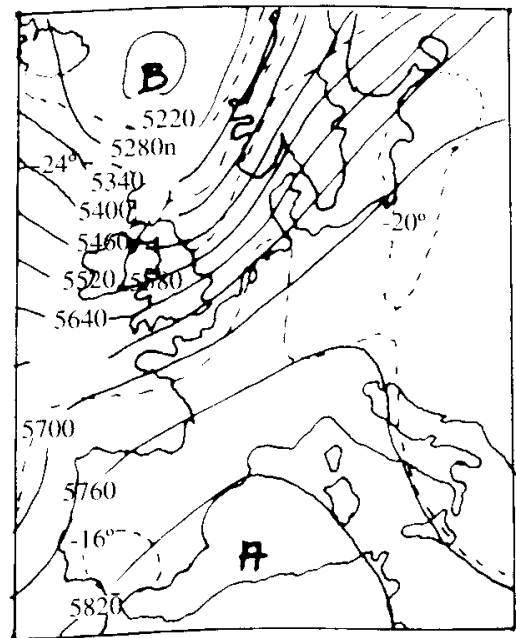

Mapa $n^{0}$ 2.b - 500 mb. a 12 h. (TMG) Día 27-10-95

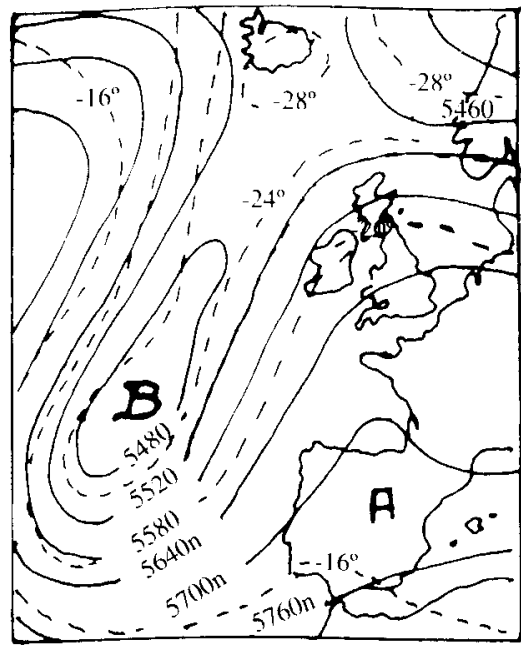

Mapa $\mathrm{n}^{0} 1 . \mathrm{d}$ - $500 \mathrm{mb}$. a $12 \mathrm{~h}$. (TMG) Día 30-10-95

Mapa del tiempo 2

Este período comienza con un descenso de las temperaturas durante los días 24 y 25 . En estas jornadas los valores térmicos se sitúan en las cotas más bajas del mes. En efecto, una borrasca centrada en la parte 
occidental de las Islas Británicas inicia su penetración y el anticiclón europeo se retira hacia el este de Europa.

El día 24 en el mapa de $500 \mathrm{mb}$. se observa que la borrasca ejerce su radio de acción sobre la Península. La corriente en chorro rodea la borrasca en la topografía de $300 \mathrm{mb}$., siendo del noroeste en Galicia y del sur en Gran Bretaña. En superficie, extremos de frentes fríos atraviesan la Península dando cielos cubiertos de nubes y escasas precipitaciones. Las masas de aire son del sudoeste, con trayectoria atlántica por niveles medios.

La llegada de las masas nubosas supone un descenso de la radiación solar que se sitúa en los niveles más bajos del mes (Aóiz 547 dKLJ/M2; Carcastillo $582 \mathrm{dKJL} / \mathrm{M} 2$ ). Asímismo el número de horas de sol se reduce (Aóiz 1,7 horas del sol; Carcastillo 2,7 horas de sol) (Gráficos 1 y 2). Sin embargo las temperaturas máximas y minimas se mantienen dentro de unos valores altos debido a la procedencia meridional de las masas de aire.

Desde el día 25 hasta el final de mes, nuestro territorio se encuentra comprendido entre un anticiclón situado en el norte de África y un sistema de borrascas, cuyo dentro se ubica a la altura del paralelo $60^{\circ}$ (Mapas 2 a, $b, c, y d)$. Ambos centros de acción envian sobre nuestra Comunidad masas de aire del sudoeste, calientes porque vienen del Atlántico sur y estables por influencia de la cresta anticiclónica meridional. Estas masas de aire se van calentando conforme atraviesan los sistemas montañosos de la Península y, al llegar a Navarra, elevan las temperaturas, sobre todo los días 26 a 28 en que se produce una pequeña ola de calor.

El día 28 es el de máximo calor en Navarra. La radiación solar es elevada y las horas de sol numerosas (Aóiz $1013 \mathrm{dKJL} / \mathrm{M} 2$ y 7 horas de sol; Carcastillo 1289 dKJL/M2 y 7,8 horas de sol). Los valores térmicos se disparan y en los Valles Cantábricos, lugares más cálidos de Navarra con situaciones del sudoeste, se alcanzan los veintiocho grados. En Pamplona se superan los veinticinco grados y en Navarra Media y la Ribera los veintiséis grados. En los Valles Pirenaicos se superan los veintiún grados. Temperaturas todas ellas muy superiores a las normales en este período del año.

En el gráfico $n^{\circ} 3$ se puede observar la temperatura a lo largo del día 28 en tres observatorios representativos. En Lekaroz (Valles Cantábricos) a las siete de la mañana se alcanza la temperatura mínima del dia, que es bastante alta y próxima a ocho grados; conforme avanza la mañana las temperaturaws aumentan llegando a su punto culminante a las dos de la tarde con veintisiete grados. A partir de aqui se inicia un descenso de los valores térmicos. El día termina con temperaturas altas. 


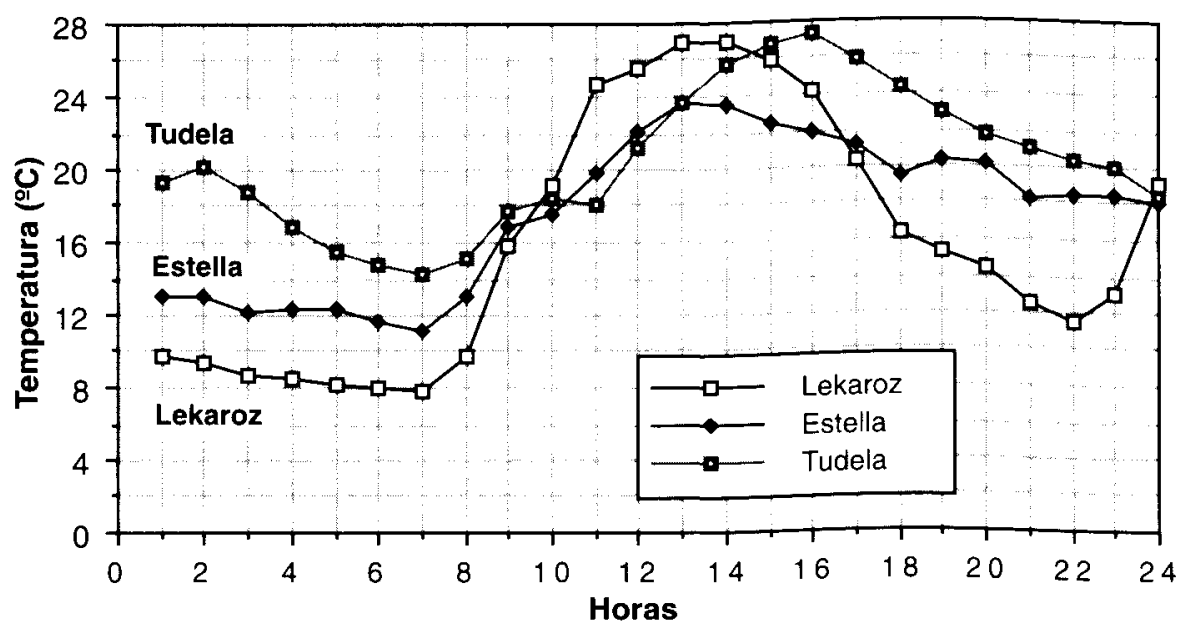

Gráfico 3. Temperaturas del día 28-10-95

En Estella (Navarra Media) las temperaturas son elevadas durante la madrugada y a las siete se mide la temperatura mínima que supera los once grados. Desde esta hora los valores térmicos suben hasta la una de la tarde en que se llega a la temperatura máxima del día $\left(23,7^{\circ}\right)$. Después, la temperatura desciende situándose a las veinticuatro horas en valores altos $\left(\mathbf{1 8}^{\circ}\right)$.

Finalmente en Tudela (Ribera navarra) los valores son también elevados durante todo el día. La temperatura mínima, muy alta, es superior a catorce grados y tiene lugar a las siete de la mañana. A partir de esta hora los valores térmicos van en aumento hasta las dieciséis horas en que se alcanzan los veintisiete grados, temperatura más alta de la jornada. Después, los valores térmicos descienden y a las veinticuatro horas se superan los dieciocho grados. Por lo tanto, temperaturas muy elevadas para estas fechas finales de octubre.

Los últimos días de octubre transcurren con dominio de las masas de aire del sudoeste, que mantienen los niveles térmicos altos. El ambiente seco es el predominante y la radiación alta, por lo que estas masas meridionales experimentan un gradual calentamiento y se sitúan en niveles elevados. En el gráfico $n^{0} 4$ se observa que la humedad relativa es muy baja en los dos observatorios considerados, lo que indica una vez más, que el mes ha sido muy poco propenso a la aparición de lluvias. Los picos altos, en los que la humedad relativa se hace más elevada, coinciden con el paso de las vaguadas poco potentes. 


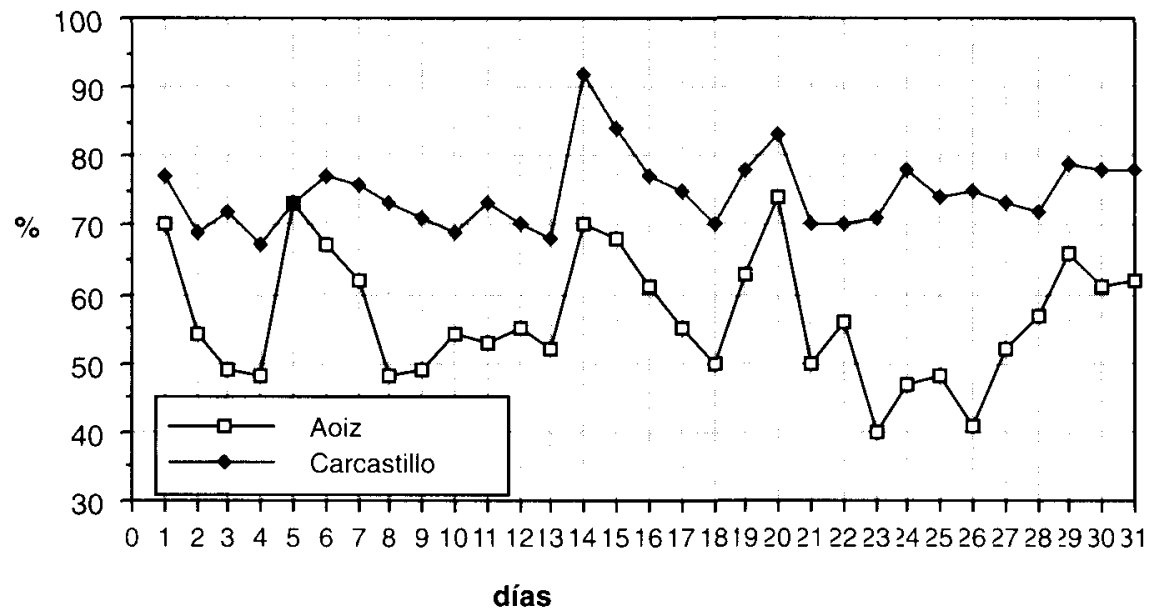

Gráfico 4. Aóiz y Carcastillo. Humedad relativa (\%).

\section{Un mes extremadamente cálido}

Dos factores contribuyeron, sin duda, a la consecución de unas temperaturas tan elevadas. En primer lugar, la dinámica atmosférica explicada anteriormente, que se caracterizó por dos situaciones claramente favorecedoras de ambientes cálidos: los anticiclones tropicales, habituales en verano, y las advecciones meridionales. $\mathrm{Y}$, en segundo lugar las características de nuestro territorio.

Los resultados térmicos por comarcas señalan la presencia de un período muy cálido que se analiza a continuación. En Navarra Húmeda (gráfico $n^{\circ} 5$ ) se registraron las temperaturas más altas de Navarra, por su situación de abrigo con respecto a las masas de aire del sur. Es cierto que con situaciones meridionales los valores térmicos se disparan en estas comarcas y dan las máximas de la Comunidad.

El accidente geográfico que más influye es la cadena divisoria BelateAzpirotz que es poco elevada por su parte meridional y bastante por su lado septentrional. De este modo, las masas de aire de componente sur tienen pocos metros que ascender y apenas se enfrían. Después de atravesar la montaña, debido al pronunciado descenso, las masas de aire experimentan un calentamiento fuerte, que supone, en definitiva, un aumento de varios grados en las temperaturas.

Las temperaturas medias de las máximas se situaron entre los veintitrés y veinticinco grados en toda la comarca. En los valles más bajos y soleados 
de la Regata del Bidasoa y del Valle del Baztán los valores térmicos fueron más altos ( Santesteban $24,7^{\circ}$, Zugarramurdi $25,2^{\circ}$, Lekaroz $25,2^{\circ}$ ) que en los valles occidentales que miran al Cantábrico y que son más monta-

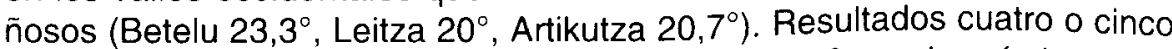
grados por encima de lo normal (Santesteban $24,7^{\circ}$ en el periodo considerado y $20,6^{\circ}$ medias históricas).

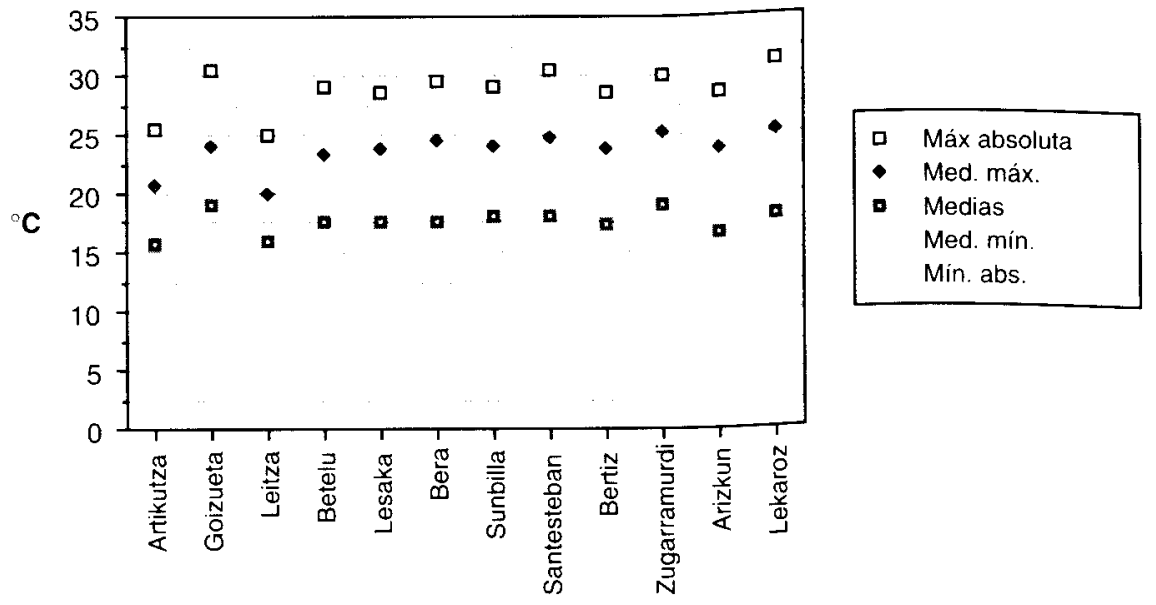

Gráfico 5. Navarra Húmeda. Temperaturas.

La temperatura media de las minimas fueron de uno o dos grados por encima de las normales ( Santesteban $11,5^{\circ}$ para el período considerado y $10^{\circ}$ para las series históricas). Siguieron destacando por su escaso frío nocturno los observatorios del Valle del Baztán y del Bidasoa que tuvieron noches excesivamente moderadas para el mes de octubre y que alcanzaron los trece grados en algunos casos. En todos los lugares se superaron los diez grados de temperatura media de las mínimas, resultados francamente altos para octubre. Las temperaturas máximas absolutas alcanzaron los treinta y un grados en Lekaroz y los treinta grados en varios observatorios soleados de la comarca (Goizueta, Zugarramurdi).

En Navarra Pirenaica es la zona en donde los registros térmicos alcanzaron unos valores excesivamente altos, en relación lo que suele ser habitual en esta zona montañosa y sometida al frío, desde los primeros meses de otoño. Lógicamente y debido al factor altura, las temperaturas se situaron por debajo de Navarra Húmeda, pero muy altas en relación con los registros históricos (Gráfico $n^{\circ} 6$ ). Es precisamente en esta zona donde el calor se dejó sentir con más intensidad en relación a lo que suele ser normal. Debido a la quebrada orografía los valores térmicos varían de unas zonas a otras. 


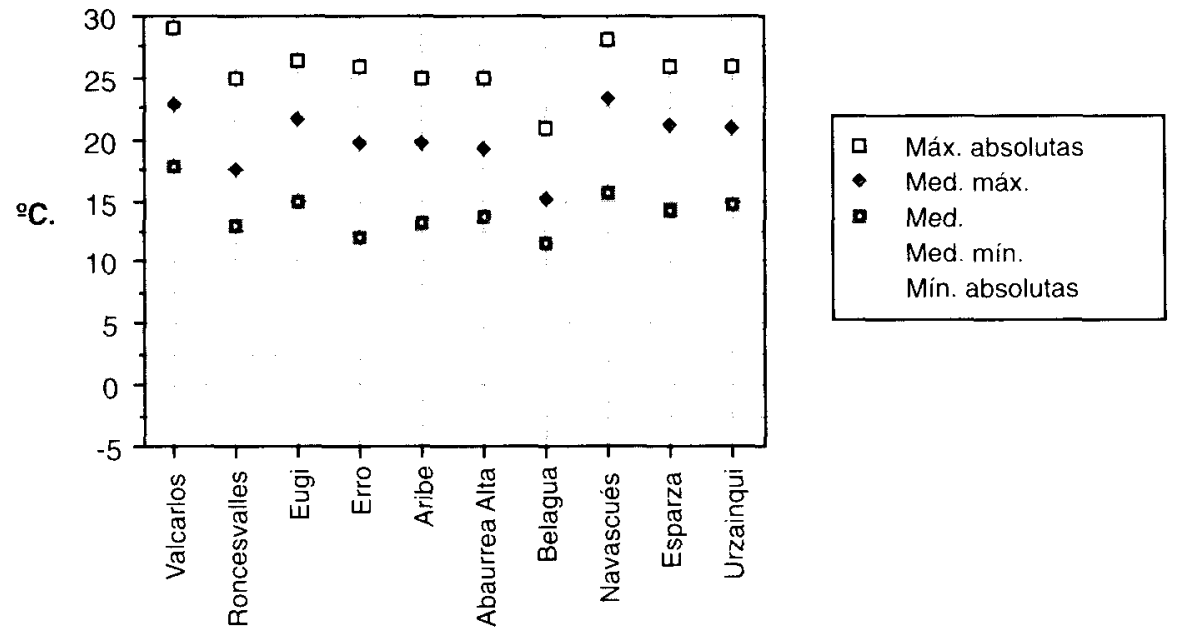

Gráfico 6. Navarra Pirenaica. Temperaturas.

Las temperaturas medias de las máximas alcanzaron los veinte grados en casi todos los valles, salvo en los lugares situados por encima de los mil metros de altura, como el Valle de Belagua, zona de Garralda-Aribe y llanada Espinal-Burguete-Roncesvalles (Abaurrea Alta 19,2 $2^{\circ}$, Belagua $15,2^{\circ}$, Roncesvalles $17,5^{\circ}$ ). Las diferencias vienen marcadas también por el mayor o menor alejamiento al mar Cantábrico o por su situación más meridional. Los lugares bajos en altitud como Valcarlos, los más próximos al mar Cantábrico, como Eugi, y los más meridionales, como Navascués, presentan valores térmicos más altos (Valcarlos $22,9^{\circ}$, Eugi $21,5^{\circ}$, Navascués $\left.23,2^{\circ}\right)$. Temperaturas siete grados más elevadas que las series históricas (Abaurrea Alta $19,2^{\circ}$ para este mes y $12,7^{\circ}$ para las series históricas).

Las temperaturas medias de las minimas fueron elevadas, cuatro grados por encima de las históricas. El enfriamiento nocturno que suele ser habitual en esta zona en octubre fue más bien débil, y las mínimas se situaron alrededor de los ocho grados. Valores cuatro grados por encima de las mínimas históricas (Abaurrea Alta $8,2^{\circ}$ para este período y $4,2^{\circ}$ series históricas). Las temperaturas máximas absolutas alcanzaron los veintinueve grados en Valcarlos y los veintiocho en Navascués.

En las Cuencas y corredores centrales de Navarra (Grafico $n^{\circ} 7$ ) también el calor fue elevado en este mes de octubre. Se trata de lugares llanos situados a sotavento de las maasas de aire del sur y en cuencas rodeadas de montañas propicias para el estancamiento de aire cálido en situación anticiclónica, coronadas con dorsales tropicales cálidas en altura. Las masas de aire meridionales experimentaron un calentamiento al paso 


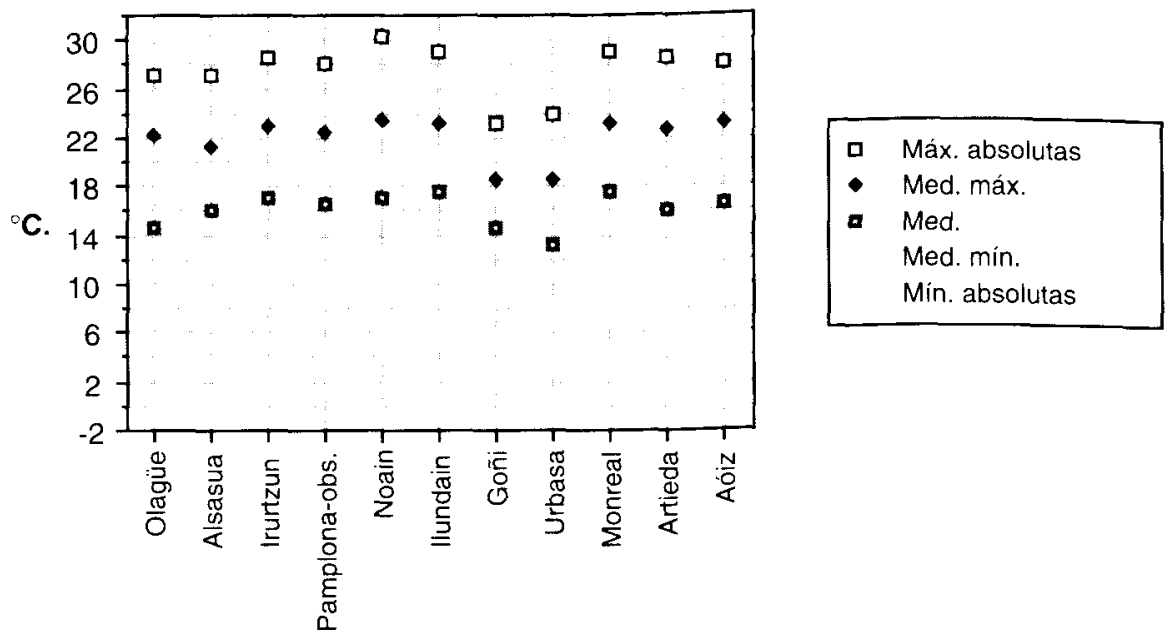

Gráfico 7. Las Cuencas.

de las Sierras Exteriores (Perdón-Alaiz-lzco) o del complejo montañoso Urbasa-Andía. El balance fue la consecución de altos registros térmicos, superiores a los de Navarra Pirenaica e inferiores a los de Navarra Húmeda.

Las temperaturas medias de las máximas se situaron alrededor de los veintitrés grados en los lugares más soleados y benignos. Se pueden considerar tres subsectores distintos dentro de la zona. El más cálido corresponde a las Cuencas de Pamplona y Lumbier-Aóiz debido a la mayor radiación medida (Pamplona-Noain $23,4^{\circ}$, Aóiz $23,1^{\circ}$ ). El segundo está representado por el Corredor del Arakil y los valles meridionales húmedos, lugares más templados por la mayor altitud y exposición al poder atemperante del mar Cantábrico (Alsasua $21,2^{\circ}$, Olagüe 22,3 $3^{\circ}$. Finalmente las zonas montañosas circundantes, debido a su altitud, dieron inferiores temperaturas (Urbasa $18,5^{\circ}$, Goñi $18,6^{\circ}$ ). Valores térmicos de cuatro grados superiores a los normales (Pamplona- obs. 22, $5^{\circ}$ para el mes de octubre del 95 y $18,8^{\circ}$ para las series históricas).

Las temperaturas medias de las mínimas fueron elevadas y normalmente superaron los diez grados, por lo que el grado de frío nocturno fue escaso. Las Cuencas de Lumbier-Aóiz y la de Pamplona dieron valores altos, destacando los observatorios de Monreal e llundain que casi alcanzan los doce grados. En las áreas montañosas de Urbasa y Andía el frío se dejó sentir algo más, dentro del ambiente moderado existente. En definitiva, temperaturas medias de las mínimas muy superiores a las históricas (Pamplona observatorio $10,5^{\circ}$ en el mes de octubre de 1995 y $8^{\circ}$ en las 
series de larga duración). Las temperaturas máximas absolutas alcanzaron los treinta grados en Pamplona-Noain.

Resultados ligeramente superiores a las Cuencas se registraron en Navarra Media (Gráfico no 8). La buena orientación con respecto a las advecciones del sur y su situación dentro de la Cuenca del Ebro favorecieron la consecución de valores térmicos altos. Los observatorios de la llanura obtuvieron temperaturas más altas que los del somontano. Los situados junto a las montañas fueron los más moderados, dentro de un ambiente cálido generalizado, impropio de octubre.

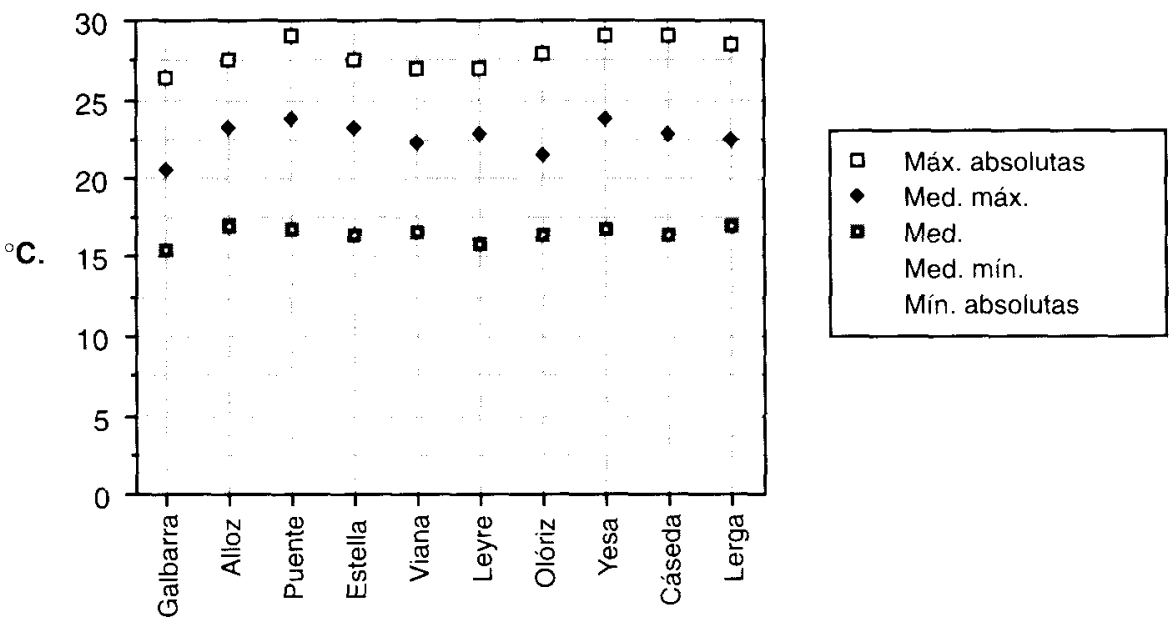

Gráfico 8. Navarra Media. Temperaturas.

Las temperaturas medias de las máximas fueron más elevadas en los lugares más soleados, situados a menor altitud, tanto en la parte occidentai como oriental. Éstas se situaron entre los veintitrés y los veinticuatro grados (Puente la Reina $23,7^{\circ}$, Yesa $23,7^{\circ}$ ). En los observatorios cercanos a las Sierras Exteriores los valores térmicos fueron inferiores (Galbarra $20,6^{\circ}$, Olóriz $\left.21,5^{\circ}\right)$. Si se comparan con las series históricas se observa el grado de calor amplio, pues se superan los cuatro grados de diferencia (Yesa $23,7^{\circ}$ en octubre de 1995 y $19,7^{\circ}$ históricas).

Las temperaturas medias de las mínimas fueron excesivamente templadas, superando los once grados en varios observatorios (Viana $11^{\circ}$, Lerga $\left.11,2^{\circ}\right)$. Valores que denotan una moderación de los registros térmicos nocturnos. Los observatorios más fríos a la noche se situaron próximos a los diez grados, con la excepción de los situados en las cadenas a bastante altitud (Leyre $8,8^{\circ}$ ). En definitiva, resultados entre uno y dos 
grados por encima de las medias históricas. Las temperaturas máximas absolutas alcanzaron los veintinueve grados en varios observatorios.

En la Ribera Navarra (Gráfico $n^{\circ}$ 9) el calor fue también elevado en este mes de octubre. Su situación en el valle del Ebro, especie de cuenca cerrada a poca altitud, favoreció sin duda, el estancamiento de masas de aire cálidas con circulación anticiclónica en superficie y dorsal tropical en altura, con calma y bastante irradiación. No es de extrañar que los resultados obtenidos sean junto con los observatorios de Navarra Húmeda los más altos de Navarra.

La uniformidad y la ausencia de fuertes contrastes térmicos fue la característica de esta comarca, dado que las diferencias en cuanto a altura son muy pequeñas. Las temperaturas medias de las máximas superaron normalmente los veinticuatro grados (Buñuel $24,2^{\circ}$, Carcastillo $24,1^{\circ}$, Caparroso $24,4^{\circ}$ ). Temperaturas superiores en cuatro grados a las históricas (Buñuel $24,2^{\circ}$ octubre 95 y $20,4^{\circ}$ series históricas).

Las temperaturas medias de las mínimas fueron elevadas para la época del año. El enfriamiento nocturno que suele tener lugar durante estas fechas no alcanzó la intensidad habitual y la moderación fue la nota caracteristica (Lodosa $11,2^{\circ}$, Sartaguda $10,7^{\circ}$ ). Las temperaturas máximas absolutas alcanzaron los treinta grados en Caparroso.

\section{Conclusiones}

El mes de octubre de 1995 entra de lleno dentro de los periodos excepcionales que se vienen sucediendo en los últimos años en nuestra Comunidad. Las temperaturas tan altas, más bien propias del estío, en un

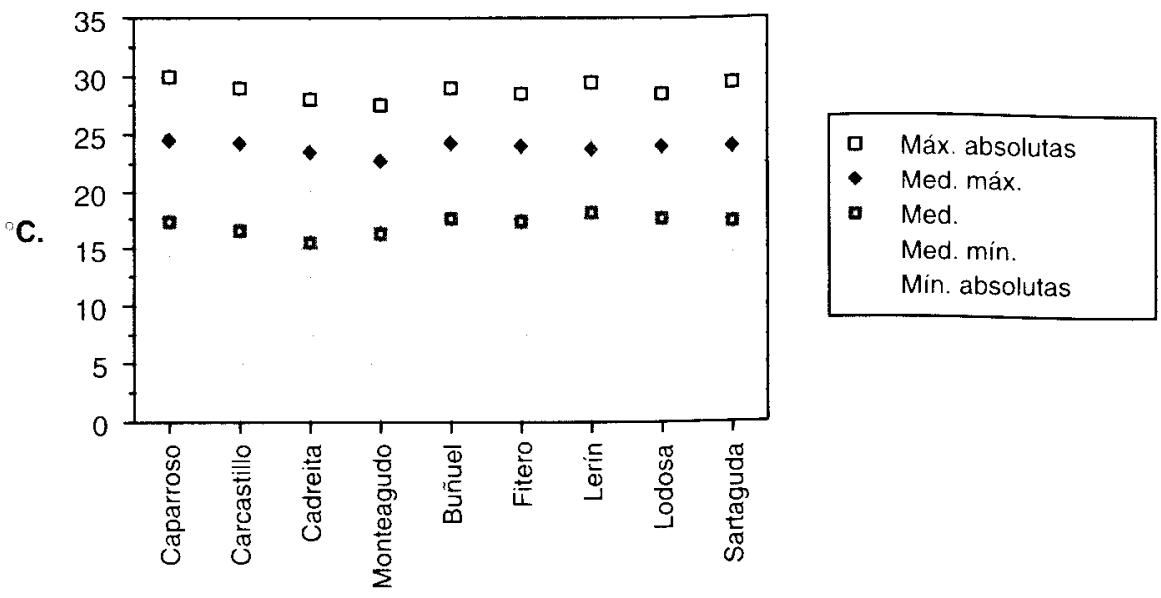

Gráfico 9. La Ribera. Temperaturas. 
mes típicamente otoñal, hacen de este mes un periodo difícil de encontrar en las series históricas amplias que se poseen. De este estudio se pueden entresacar las siguientes conclusiones:

1. Las principales manifestaciones de este período anormal fueron las temperaturas. La originalidad de este mes reside, ante todo, en las elevados valores térmicos obtenidos, desconocidos en la mayor parte de los observatorios de Navarra si se observan las series históricas de los cuatro observatorios seleccionados (Gráficos 10, 11, 12 y 13).

Esta conclusión viene avalada por los datos que a continuación se exponen. En el observatorio de Santesteban perteneciente a los Valles Cantábricos (Navarra Húmeda) la temperatura media del mes de octubre de $1995\left(18,1^{\circ}\right)$ es la más alta desde el año 1941. En Abaurrea Alta, estación situada en los Valles Pirenaicos (Navarra Pirenaica), la temperatura media de octubre de $1995\left(13,8^{\circ}\right)$, desde el año 1941 sólo fue superada por el año 1951 que alcanzó los catorce grados.

En Pamplona-observatorio, estación situada en las Cuencas, la temperatura media del mes de octubre de $1995\left(16,7^{\circ}\right)$ es la más alta desde el año 1941 junto con la del año 1968. Y finalmente en Carcastillo-la Oliva, observatorio de la Ribera, la temperatura media del mes de octubre de $1995\left(16,7^{\circ}\right)$ es la más alta desde el año 1941 junto con la de 1947. Temperaturas de tres a cinco grados por encima de las medias habituales, según las distintas comarcas.

2. Tres son las causas principales que dieron lugar a este período extremadamente cálido.

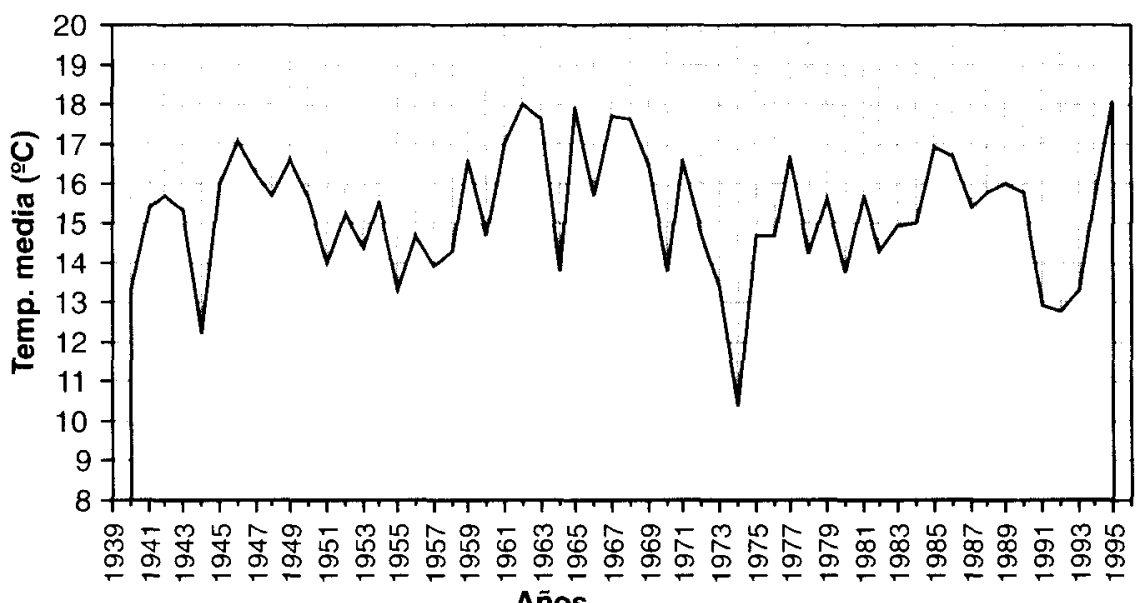

Gráfico 10. SANTESTEBAN. Temperaturas medias de octubre. (Años 1940-1995). 


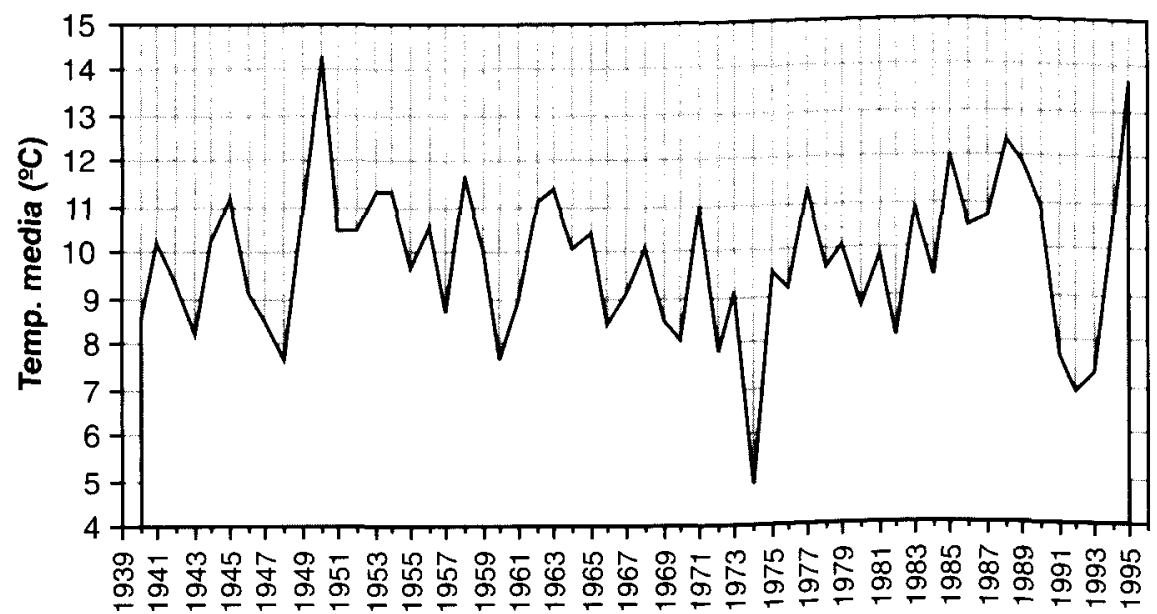

Años

Gráfico 11. ABAURREA ALTA. Temperaturas medias de octubre. (Años 1940-1995).

a. La primera de ellas es la circulación de la atmósfera. En efecto, los dos tipos de situaciones atmosféricas principales que afectaron a Navarra a lo largo del mes, las anticiclónicas, coronadas con dorsales tropicales en altura que supusieron más de la cuarta parte de los días y se caracterizaron por proporcionar jornadas muy cálidas, y las situaciones meridionales del sur y del sudoeste que afectaron a más de la tercera parte de los días. Por lo tanto, condiciones propicias de la atmósfera para obtener resultados térmicos elevados.

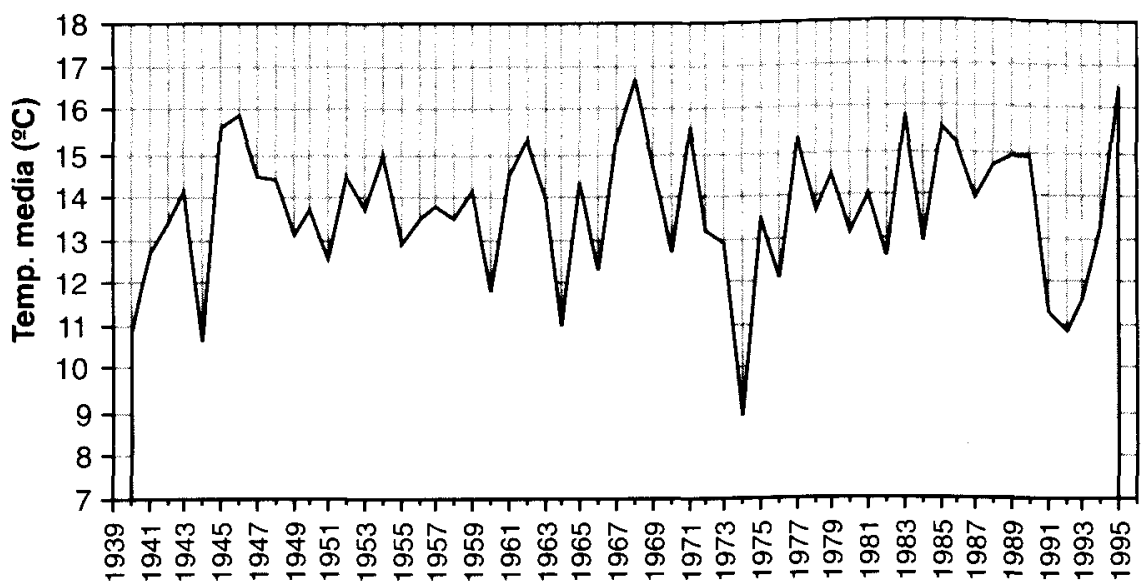

Años

Gráfico 12. PAMPLONA-OBS. Temperatutas medias de octubre. (Años 1940-1995). 


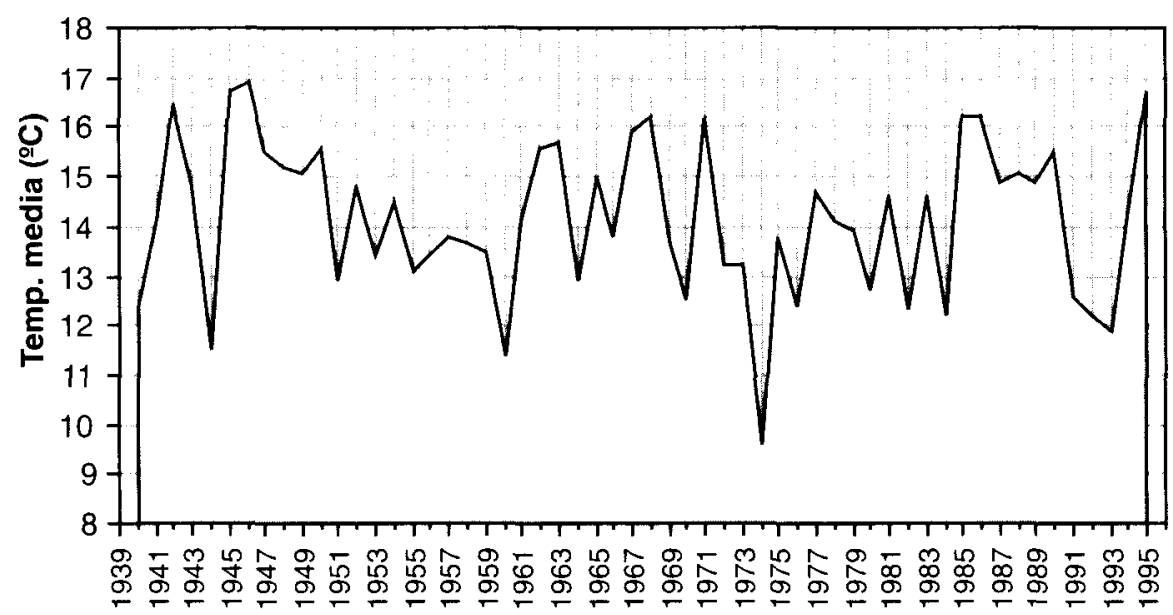

Años

Gráfico 13. CARCASTILLO. Temperatutas medias de octubre. (Años 1940-1995).

Por el contrario, las situaciones que dan lugar a descensos térmicos y temperaturas frias, es decir, las de primer y cuarto cuadrante, y los embolsamientos fríos sobre nuestra vertical, estuvieron ausentes, por lo que no hubo posibilidad de descensos térmicos acusados a lo largo del mes.

Las situaciones del norte que suelen estar presentes en el mes de octubre no aparecieron en esta ocasión. De este modo el cierzo frío de procedencia septentrional no llegó a Navarra y, por lo tanto, no dio lugar al frecuente descenso térmico habitual en estas fechas. Por otra parte, la escasa presencia de lluvia no contribuyó a refrescar el ambiente. Así pues, la dinámica atmosférica se sale de lo que es normal en el mes de octubre y muestra un predominio de situaciones más propias de la estación estival que del otoño. La alternancia de días anticiclónicos, que dan lugar a veranillos suaves, con borrascas del frente polar que producen lluvias y descensos térmicos, frecuentes en otoño, estuvieron ausentes.

b. La radiación global media del mes fue muy elevada y superior a las medias históricas (Aguilar de Codés 1163,7 dKJ/M2 , Aóiz 1185,5 dKJ/M2, Carcastillo 1316,6 dKJ/M2). También las horas de sol fueron numerosas para el mes considerado (Aguilar de Codés 6,8 horas de sol, Aóiz 7,3 y Carcastillo 8)

c. La situación y el relieve de Navarra fueron factores decisivos que contribuyeron a la aparición del anormal mes y que individualizan nuestra Comunidad de otras regiones españolas. El territorio de Navarra desempeñó un papel importante. Por una parte los macizos montañosos favorecieron el 
calentamiento de las masas de aire a sotavento de las montañas con situaciones de sur y, por otra, las cuencas, rodeadas de montañas, propiciaron el embalsamiento de aire cálido y su posterior caldeamiento en jornadas con insolación y la radiación elevadas.

3. El comportamiento climático fue diferente en las distintas comarcas navarras. Dentro de un calor generalizado, los observatorios de los Valles Cantábricos situados a escasa altura fueron los más cálidos junto con algunos lugares de la Ribera. Las Cuencas y Navarra Media anotaron registros elevados, pero inferiores a los anteriores. Pero fue en los Valles Pirenaicos, en donde el calor alcanzó una intensidad grande de acuerdo con to que es normal en esta época del año. Aunque los valores fueron los más bajos por ser zona de montaña, es la zona en donde más diferencia hubo en relación a lo que es normal. En definitiva, todas las comarcas navarras, sin excepción, midieron temperaturas muy elevadas y desconocidas en la mayor parte de los observatorios.

4. Las consecuencias fueron negativas para los intereses de nuestra Comunidad. Octubre, mes lluvioso en Navarra, no recibió en esta ocasión las precipitaciones deseadas y contribuyó a extender la pertinaz sequía que se padecía desde marzo y a dejar los pantanos de Navarra a niveles mínimos (el Embalse del Ebro de una capacidad útil de $540 \mathrm{hm}^{3}$, el agua embalsada no llegaba a $100 \mathrm{hm}^{3}$; el Embalse de Yesa de una capacidad útil de $447 \mathrm{hm}^{3}$ no llegaba ni a $50 \mathrm{hm}^{3}$, el agua embalsada). Además, las altas temperaturas favorecieron la evapotranspiración de las plantas.

Por lo tanto, varias circunstancias dieron lugar a uno de los octubres más cálidos del siglo: las masas de aire cálidas, protagonizadas por las dorsales cálidas y las situaciones meridionales; la radiación global elevada y las numerosas horas de sol; y el relieve de Navarra que propició el aumento de temperaturas a sotavento de las montañas.

\section{BIBLIOGRAFIA}

Albentosa, L. M. (1973) : Los climas de Cataluña. Estudio de climatologia dinámica (Tesis de doctorado), Departamento de Geografia, Universidad de Barcelona.

Artery, R.; Grisollet, H. y Guilmet, B. (1973): Climatologie. Méthodes et pratiques, Paris, Gauthiers-Villards.

CAPEl Molina, J. (1981): Los climas de España, Barcelona, Oikos-tau.

CAPEL MOLINA, J. (1978): "Avance sobre las invasiones de aire cálido en la Península lbérica", en Cuadrnos Geográficos (vol. homenaje al protesor Dr. D. J. Bosque Maurel). Universidad de Granada.

Creus (1986): Climatología (Gran Atlas Geográfico e Histórico de Navarra), Pamplona, Caja de Ahorros Provincial de Navarra, pp. 83-90.

Creus Novau, J. (1990): Climatologia (Gran Enciclopedia Navarra), Caja de Ahorros de Navarra, Pamplona. 
Elias Castillo, F. y Ruiz Beltrán, L. (1986): Caracterización agroclimática de Navarra. Pamplona, Ministerio de Agricultura, Pesca y Alimentación y Departamento de Agricultura, Ganadería y Montes del Gobierno de Navarra, 226 p.

Font Tullot, I. (1988): Historia del clima de España, cambios climáticos y sus causas, Madrid, I.N.M., 298 p.

Garcia de Pedraza, L.(1964): La predicción del tiempo en el valle del Ebro, Madrid, Servicio Meteorológico Nacional, Serie A-38.

Garcia Fernandez, J.(1986): El clima de Castilla y León, Valladolid, Ámbito.

Mensua (1968): "la zonificación bioclimática de Navarra», en of. D. José María Lacarra de Miguel, Zaragoza, $p p$

Olcina Cantos, J. y Rico Amoros, A. (1995): "Sequias y golpes de calor en el Sureste ibérico: efectos territoriales y económicos". Alicantes, Investigaciones Geograficas, enero-junio, pp. 47-79

Olcina Cantos, J. (1994): Riesgos climáticos en la Peninsula lbérica, Madrid, Penthalon, 440 p.

Olcina CANTOS, J. (1995): Factor climático y la ordenación del territorio: los riesgos climáticos, Jaca, 2 Reunión del grupo de climatología de la A.G.E., Instituto Pirenaico de Ecología, pp. 15-69.

Olcina Cantos, J. y Rico Amoros, A. (1995): "Sequias y golpes de calor en el Sureste ibérico: efectos territoriales y económicos", Alicantes, Investigaciones Geograficas, enero-junio, pp. 47-79

Pegur, $\mathrm{CH}$. (1961): Précis de climatologie, Paris, Masson.

Pejenaute Goñı, J. (1990): Tipos de tiempo y clima de las Comarcas Navarras (tesis de doctorado), Pamplona, Gobierno de Navarra, Príncipe de Viana.

Pejenaute Goñl, J.M. (1989): "Atmósfera y territorio. Factores que condicionan el clima de Navarra" (Lección apertura de curso 1989-90), Centro Asociado de la UNED en Pamplona, serie lecciones, $25 \mathrm{p}$.

Pejenaute Goñl, J.M. (1990): "Introducción al estudio de la climatologia en Navarra", Lurralde,13, pp. 43-62, INGEBA, San Sebastián.

Pejenaute Goni, J.M. (1992): El clima de Navarra, Pamplona, Ediciones Eunate, 223 p.

Pejenaute Goñi, J.M. (1993): El clima de Pamplona, Pamplona, Ayuntamiento de Pamplona, $104 \mathrm{p}$.

Pejenaute GoÑi, J.M. (1994): El tiempo en Navarra, Pamplona, Gobierno de Navarra, Departamento de Agricultura, Ganaderia y Montes, Colección Temas de Navarra, n 12, 104 p.

Pejenaute GoÑI, J.M. (1990): "El período seco otoño-invierno 88-89 en Navarra", Notas y Estudios de Ciencias Sociales 3 ,Pamplona, Centro Asociado de la UNED, 1990, pp. 95-130.

Pejenaute Goñi, J.M. (1992): "La ola de calor de agosto de 1991 en Navarra", Notas y Estudios de Ciencias Sociales 5, pp. 119-152 Pamplona, Centro Asociado de la UNED, 1992.

PEJENAUTE Goñı, J.M. (1993): "Estudio de un otoño lluvioso en Navarra", Espacio, tiempo y forma, Serie VI, Geografía, t. 6, pp. 41-78.

RIVERA, A. (1978): "La ola de calor del 14 al 19 de julio de 1978 en algunas regiones de la mitad suroriental de la Península lbérica», Paralelo $37^{\circ}$, pp. 117-145, Departamento de Geografía, Colegio Universitario de Almería

Ruiz URREstaRAzU, E.(1982): La transición climática del Cantábrico Oriental al Valle Medio del Ebro, Vitoria, Diputación Provincial de Alava, $651 \mathrm{p}$.

VALERO AMAT, P. (1992): Olas de calor y altas temperaturas en tierras alicantinas. Memoria de Licenciatura. Instituto Universitario de Geografía, Universidad de Alicante, $1283 \mathrm{pp}$.

VILLA, D. (1988): "Fuerte ola de calor en el Mediterráneo Oriental en julio de 1987», Calendario Meteorológico de 1988, Madrid, Instituto Nascional de Meteorología, pp. 191-193. 